\title{
Plastic Clashes: Competition among Closed and Open Systems in the Credit Card Industry*
}

\author{
Fabio M. Manenti ${ }^{\dagger} \quad$ Ernesto Somma
}

October 2003

\begin{abstract}
This paper analyses market competition between two different types of credit card platforms: not-for-profit associations and proprietary systems. The main focus is on the role of the interchange fee set by not-forprofit platforms. We describe the sterilising role of the interchange fee: when the interchange fee is set so as to maximise the sum of issuers' and acquirers' profits, the equilibrium values of platforms' profits, of the sum of the fees charged by each platform and their market shares are independent of the competitive conditions within the not-for-profit platform and are affected by the strength of inter-platform competition. We also show that the imposition of a ban on the setting of the interchange fee has ambiguous effects on the profit of the proprietary system.
\end{abstract}

J.E.L. codes: G21, L13, L31, L42.

Keywords: two-sided markets, network externalities, credit cards, interchange fee.

${ }^{*}$ Paper completed while the authors were visiting the University of California, Berkeley. Paper presented at 2003 IIOC (Boston) and at the 2003 EARIE annual conference (Helsinky); Marius Schwartz gave a significant contribution on an earlier version of the paper. We would also like to thank Hal Varian, Bruno Parigi, Joshua Gans, Julian Wright and Benedetto Gui for useful comments. The seminar audiences at the universities of Padova, Lecce and Pescara are also acknowledged. The usual disclaimer applies.

$\dagger$ The financial support from the Education Abroad Program of the University of California is gratefully acknowledged. The author wishes to thank Glenn Woroch for the hospitality provided. Address for correspondence: Dipartimento di Scienze Economiche "M. Fanno", Università di Padova, Via del Santo 33, 35123 PADOVA (Italy), Tel. (39) 49 8274238, email: manenti@decon.unipd.it

${ }^{\ddagger}$ Dipartimento di Scienze Economiche, Università degli Studi di Bari, Via C. Rosalba 53, 70124 BARI (Italy), Tel. (39) 80 5049100, email: e.somma@dse.uniba.it 


\section{Introduction}

In the market for credit cards, two types of systems operate: not-for-profit associations and proprietary for-profit systems. The not-for-profit associations, like Visa and Master Card, are owned and controlled by members (banks and other payment entities) who issue cards to consumers and process the merchants' transactions. Often the two payment card entities, those issuing the card to consumers and those that process the merchants' transactions are different. The first type of entity is called issuer, the second acquirer. All fees are set and collected by members (issuers and acquirers) directly whereas the platform is paid membership fees to cover platform related costs. Consumers' fee can take different forms, per-transaction fee, flat fee, two-part tariff and are paid to the issuing entities. Merchants pay a merchant discount, generally a percentage of the amount of the transaction, to acquirers.

Also platforms cooperatively set interchange fees; these are fees that acquiring banks pay to banks that issue cards for each transaction between their respective customers, merchants and cardholders.

The second type of platforms are proprietary, vertically integrated for-profit organisations that directly issue cards, acquire merchants and set their fees. A main example of this type of platforms is American Express.

Since 1984, when National Bancard Corporation unsuccessfully sued Visa claiming that Visa's interchange fee was an illegal agreement, the business model of these two types of organisations has been the focus of increasing attention by economists and regulators and the collective setting of the interchange fee by associations is currently under close scrutiny in many countries. The opportunity of regulation of payment systems, and in particular of interchange fees, has been considered by the Office of Fair Trading in the U.K. and, recently, also by the European Commission. In July 2002, the European Commission ${ }^{1}$ declared the multilateral settings of the Visa interchange fees an anti-competitive practice; nevertheless, the Commission has decided to exempt, under the European Union competition rules, the multilateral interchange fees for cross-border Visa card payments, provided that these fees are capped at the level of relevant costs. The Reserve Bank of Australia has recently proposed to introduce a cost-based regulation of the interchange fees in order to promote access of banks into credit card associations ${ }^{2}$.

The aim of this paper is to model competition between for-profit and not for-profit credit card schemes focusing on the strategic role of the interchange fee. This analysis raises interesting questions due to the different organisational

\footnotetext{
${ }^{1}$ See European Commission (2002).

${ }^{2} \mathrm{~A}$ critical discussion of the arguments put forward by the Reserve Bank of Australia can be found in Visa (2002).
} 
structures of the two platforms.

The literature on the economics of credit cards is by now quite well developed and includes Frankel (1998), Evans and Schmalensee (1999), and Chang and Evans (2000) which discuss arguments for and against the allegation of price-fixing. ${ }^{3}$. The platform enables transactions that are carried out by two sets of agents, buyers and sellers, whose decisions to join the platform are taken in an uncoordinated fashion. To be economically viable, platforms have to get both sides on board: buyers' benefits from joining a platform are increasing in the number of merchants where their card is accepted; at the same time merchants' benefits from joining are higher the more widespread the use of the card among consumers ${ }^{4}$. This type of interactions raises a coordination problem for the platform owner who has to balance the two sides of the market so as to maximise the economic value of the platform. This is not the usual problem faced by imperfectly competitive firms. Absent these complementarities, firms usually raise price and restrict output in order to maximise profits; in two-sided markets, firms have to price in order to coordinate customers' choices independently taken on the two $\operatorname{sides}^{5}$.

A small number of recent papers discusses the issues involved in price setting in two-sided markets and analyses the role played by interchange fees in the credit cards market.

Rochet and Tirole $(2002,2003)$ develop a model of platform competition with two-sided markets which is general enough to encompass a number of different industries. For a wide range of governance structures they show how the pricing structure of firms operating in two-sided markets is devised so as to get both sides on board. With competing platforms (either for-profit or not-forprofit), the optimal price structure depends on the split of total costs between issuers and acquirers, the demand elasticities as well as the different degrees of competition on the two sides of the market. Schmalensee (2002), analyses the determinants of the optimal interchange fee set by a single platform under different assumptions about the degree of competition on the issuers' and acquirers' side. He derives a decomposition of the optimal interchange fee in two

\footnotetext{
${ }^{3}$ For a synthesis of the recent theoretical literature on the determination of the interchange fee by payment card associations, see Rochet (2003).

${ }^{4}$ Evidence on the benefits from credit card usage for buyers includes the possibility to conclude transactions whether or not the cardholder is known to the merchant, the security advantages due to the possibility to minimise holding of cash balances, the possibility to do transactions on-line or over the phone, to make purchases abroad. Merchant benefits include convenience effects in transactions were the alternative method of payment is more costly as in on-line sales and mail-order, risk shifting benefits when the risks of fraud or default are passed to the issuers.

${ }^{5}$ A general discussion of the economics of two sided markets is in Parker and Van Alstyne (2000) and Armstrong (2002).
} 
parts; one depends on the differences in demand elasticities faced by acquirers and issuers, the other depends on the cost differences of the two sides. He also demonstrates, for the case of linear demands that, the privately optimal interchange fee corresponds to the socially optimal. More generally, the two are not equal but there is no clear bias between their levels; this conclusion is consistent with the results of Rochet and Tirole (2002, 2003).

Recently, Guthrie and Wright (2003) extend Rochet and Tirole (2003) model of platform competition by considering strategic interactions of merchants; they study competition between two identical payment networks and show that, quite surprisingly, network competition may lead to merchants being charged more and consumers less (that is, higher interchange fees).

Wright (2002) analyses how the imposition and the lift of the rule, commonly found in many platforms, that forbids merchants to charge different prices to customers using different means of payment (also known as nosurcharge rule), affects the platform's choice of the interchange fee and total welfare. Absent the no-surcharge rule, if merchants have market power they will extract surplus from the inframarginal cardholders and consequently there is underprovision of cards and too little usage. Under these circumstances, both the platform and a regulator would prefer the reinstatement of the rule and will set a common socially optimal interchange fee. Such a fee can appropriately allocate costs and benefits to cardholders and merchants under two conditions: merchants have significant market power and the nosurcharge rule is in place. Gans and King (2002) construct a model based on the assumptions laid out in the reform proposals of the Reserve Bank of Australia (RBA) and test for the theoretical soundness of the actions proposed by RBA. They analyse the case of a single platform with a number of competing issuers and acquirers and show that if two-part tariffs are levied by issuers and acquirers, then the optimal interchange fee is independent of the competitive conditions on the two sides; if fees are linear, the optimal interchange fee is increasing in the level of acquirers' competition and decreasing in the level of issuers' competition. Although framed in different settings, these models share the common result that regulation imposing a ban on the interchange fee or a cost-based mechanism for the determination of buyers' and merchants' fees are very likely to reduce rather than increase social welfare due to the difficulties involved in the determination of the socially optimal interchange fee. Another common characteristic of the literature reviewed above, is that all models do not consider explicitly the competition between not-for-profit and for-profit platforms which, instead, is the primary focus of this paper.

Competition between these two types of platform raises interesting questions due to their asymmetries. For-profit platforms are vertically integrated and have two separate instruments, buyers' and merchants' fees, and optimise 
on both; the not-for-profit platforms have only one instrument at their disposal - the interchange fee - being the other fees the result of intra-platform competition between its members. Moreover, if we assume that the degree of differentiations between platforms is higher than within the same platform, we might expect the interchange fee to play a role in neutralising the excess of intra-network competition.

We analyse what is the role of the interchange fee and how it can be used by not-for-profit platforms in the competition with a different type of platform.

We assume duopolistic competition among platforms and intense intraplatform competition among issuing and acquiring banks. Using a generalised Hotelling model we derive a number of results concerning the competitive role played by the interchange fee, its effect on prices, total output and profits. Also we study how intra-platform and inter-platform competition affect the optimal interchange fee.

The main theoretical contribution of this paper is to highlight the different effects of inter-platform as opposed to intra-platform competition on the interchange fee and the immunisation role played by this latter with respect to the degree of intra-platform competition. When the interchange fee is set so as to maximise the sum of issuers' and acquirers' profits, the equilibrium values of platforms' profits, price levels and their market shares are independent of the competitive conditions within the not-for-profit platform and are affected by the strength of inter-platform competition. We show how, in equilibrium, the not-for-profit platform, by appropriately setting its interchange fee, is able to make its competitive stance against the rival platform independent of its internal competition.

Variations in the strength of competition, both inter and intra-platform, affects the level of the optimal interchange fee. An increase in the level of intraplatform competition, generating either from the issuers' or the acquirers' side, induces a change in the optimal interchange fee that increases the price of the less competitive side. This implies that if, for example, the acquirers' side is less competitive than the issuers' side, a further increase of competition in the issuers' side will lead to an increase of the optimal interchange fee. If interplatform competition is not too asymmetric on the two sides, changes in its level produce the same effects on the optimal level of the interchange fee as those discussed above for intra-platform competition.

Finally, we show that banning the setting of the interchange fee does not necessarily make things better for the for-profit platform. Our results do not depend on the strength of cross-network effects and hold with general trading patterns between buyers and sellers.

The rest of the paper is organised as follows: section 2 sets up the model of credit card platforms competition and describes consumers' and sellers' be- 
havior; the main results are derived and discussed in section 3 . In section 4 we show that the basic economics of the model remain largely unchanged when network effects at the individual level or more general trading patterns are introduced in the model. Section 5 concludes.

\section{The model}

\subsection{Assumptions}

We model the competition between two credit card platforms. Platform 1 is a not-for-profit association jointly run by its members; platform 2 is a proprietary profit maximising platform. In platform 1, the fees charged to buyers and sellers are independently set by the issuing and acquiring banks respectively. Platform 1 also sets an interchange fee, denoted by $a$, which is set so as to coordinate the two sides of the market. It is customarily assumed that the interchange fee flows from acquirers to issuers. We adhere to this custom and we allow $a$ to take positive or negative values.

The objective of platform 1 is to maximise the total value of the network which is given by the sum of its member's profits. Without loss of relevance we simplify the analysis by neglecting any fixed or variable cost directly incurred by the platform. Without platform costs, the zero profit condition at platform level implies that the total amount of interchange fees paid by one side exactly offsets the amount received by the other. In line with the existing literature we make the simplifying assumption that issuers and acquirers are different entities ${ }^{6}$.

Platform 2 directly sets the fees for the two sides of the market. We restrict attention to linear per-transaction prices and do not consider two-part tariffs. Although annual fees for cardholders are often present, options without such fixed fees are frequently available and merchants generally face no or very low fixed fees for accepting cards.

Economic value is created by "transactions" between pairs of end users, buyers and sellers; these transactions are mediated by a platform. We assume that neither buyers nor sellers multihome, so they can be affiliated to at most one platform and that the two populations of buyers and sellers have mass one. The "no-multihoming" assumption is taken for simplicity but it also reflects the observation of what often happens in reality where very few individuals adopt all the available cards and very few merchants accept all of them.

\footnotetext{
${ }^{6}$ This assumption makes the exposition simpler but it does not affect our main results.
} 


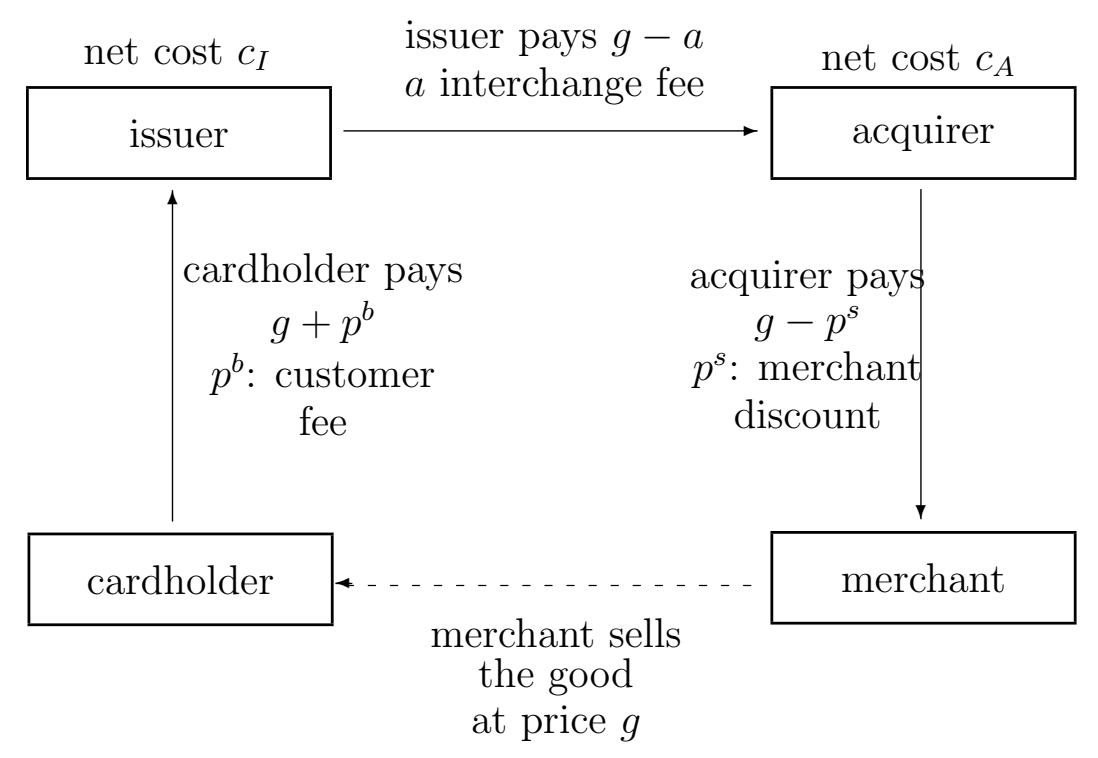

Figure 1: Flow of funds in not-for-profit platforms

Consider a (buyer, seller) pair; without loss of generality, we can assume that each such pair corresponds to one potential transaction. Actual transactions can take place only if both parties are affiliated to the same platform.

We also assume that both platforms impose a no-surcharge rule that prohibits merchants to pass some or all of the costs of processing credit cards transactions to those buyers who prefer credit card to cash. Explicit no-surcharge rules are quite common for associations like Visa and Master Card and, even when not explicitly forbidden, in many countries surcharging is rarely observed. The two platforms offer a differentiated service to both cardholders and merchants. On platform 1, issuing banks compete for cardholders and acquiring banks compete for merchants. We assume that intra-network differentiation is small compared with inter-network differentiation.

Since they play an important role in our model, it is useful to define neatly the two concepts of intra-platform and inter-platform competition. The former relates to the competitive conditions within platform 1 and it is affected by the number of issuing and acquiring banks operating on that platform and the degree of differentiation in the services they provide. The latter concept relates to the degree of competition between the two platforms on both sides of the market. The intensity of competition depends on the degree of substitutability between the two platforms.

Figures 1 and 2 graphically summarise the flows of funds within the two platforms. 


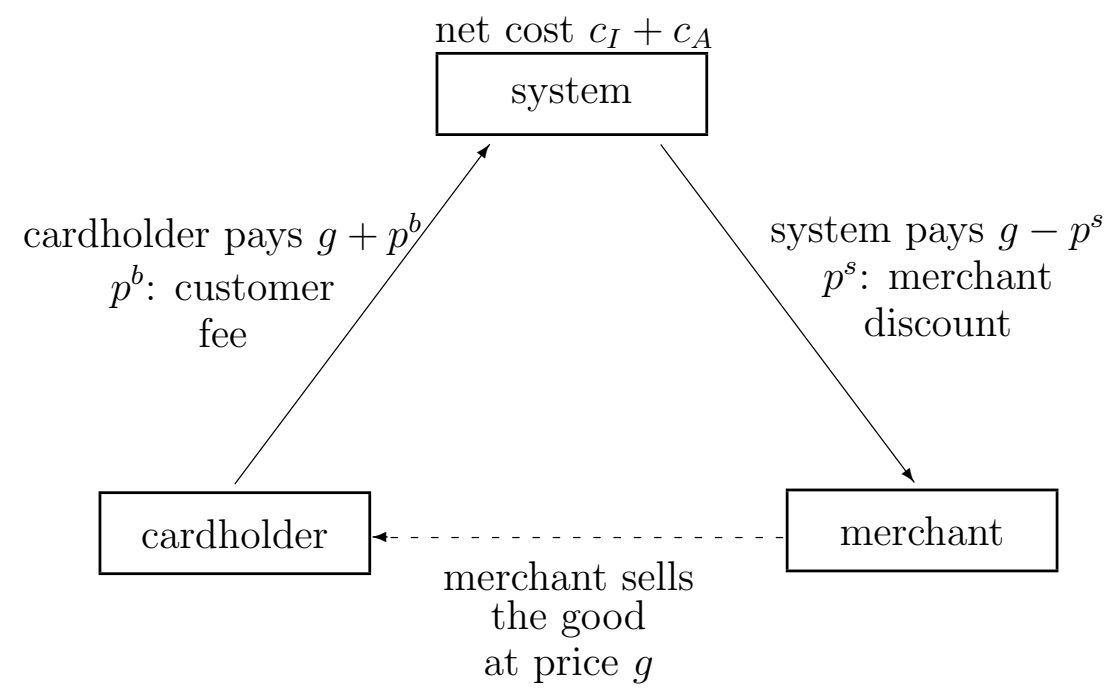

Figure 2: Flow of funds in for-profit platforms

The timing of the model is the following: in the first stage platform 1 sets its interchange fee, in stage 2 market competition takes place between member banks and platform 2 which compete on prices. Since the interchange fee is fixed by the association only periodically, it is natural to assume that $a$ is set before affiliated banks compete in prices. We assume that side payments between issuing and acquiring banks are not allowed; this implies that the optimal interchange fee cannot yields negative profits for member banks.

Both sides of the market are described using a variation of the standard Hotelling model with the two platforms located at the two ends of a unit length segment. Buyers and sellers are uniformly distributed along the line representing each side of the market.

\subsection{Intra-platform competition on platform 1}

Issuers compete for cardholders while acquirers compete for merchants. The fee charged to cardholders and merchants are set independently by member banks.

Issuers and acquirers have constant marginal costs denoted by $c_{A}$ and $c_{I}$ respectively ${ }^{7}$. Considering the interchange fee, total per transaction costs be-

\footnotetext{
${ }^{7}$ Issuing costs are generally higher than acquiring costs since they include the costs of certain specific services offered to cardholders; these services include: transaction processing, payment guarantee and the provision of free funding periods.
} 
come:

$$
c_{A}+a, \quad c_{I}-a
$$

For later use, let define the platform total per transaction cost: $c=c_{I}+c_{A}$.

Affiliated banks on the two sides of the market are little differentiated; as in Rochet and Tirole (2003), we assume that there exists an intense intranetwork competition resulting in equilibrium prices charged on merchants and cardholders that depend on the degree of competition between issuing and acquiring banks and on their marginal costs, $c_{i}$ and $a$. For the moment, let us proceed in the simplest possible way and assume that equilibrium prices are linear in banks' marginal cost; formally, this is equivalent to assume exogenous price-cost markups on the two sides of the market:

$$
\begin{array}{lll}
p_{1}^{s *}=\sigma\left(c_{A}+a\right) & \Rightarrow & \frac{p_{1}^{s *}-\left(c_{A}+a\right)}{p_{1}^{s *}}=\frac{\sigma-1}{\sigma} \\
p_{1}^{b *}=\beta\left(c_{I}-a\right) & \Rightarrow & \frac{p_{1}^{s *}-\left(c_{I}-a\right)}{p_{1}^{b *}}=\frac{\beta-1}{\beta}
\end{array}
$$

where $\sigma$ and $\beta$ are constant margins and strictly greater than 1 and can be interpreted as the degree of intra-network competition between acquiring and issuing banks respectively. This amounts to assume that members of the association are little differentiated in a direction orthogonal to that of platform differentiation. In a generalised model of Hotelling competition between platforms, the only admissible equilibrium prices for platform 1 are given in (2) and (3). Platform 2 anticipates this, and sets its optimal prices.

\subsection{Buyers' behavior}

Without loss, we assume that the buyer's benefit from consumption net of the price of the good, is independent from the mean of payment used (cash or card) and we assume this net utility to be zero.

Given linear per-transaction prices, the actual benefit that a buyer enjoys when adopting a card depends on the per transaction benefit. This way of modeling buyers' behavior, which is common in the literature, is consistent with the observation that individuals when endorsing a platform do not know in advance how many transactions they will realise and therefore they take the adoption decision on a per transaction basis. ${ }^{8}$ This also helps to simplify the model considerably, since we do not have to model the uncertainty of each individual future number of purchases.

\footnotetext{
${ }^{8}$ Often, and equivalently, it is assumed that independently on their affiliation, buyers make a fixed number of purchases; again, this implies that they affiliate to the platform which guarantees the higher per-transaction benefit.
} 
Absent multihoming, each buyer is confronted with the choice of which platform to adopt, given that the two networks are differentiated. We model this choice within an Hotelling framework; let $k$ denote the transportation cost incurred by each consumer and let $M_{j}, j=1,2$ be the expected number of merchants operating on platform $j$. Expressions (4) and (5) give the individual per-transaction utility from using the card issued on platform 1 and by platform 2 respectively

$$
\begin{gathered}
v^{b}\left(M_{1}\right)-p_{1}^{b}-k x \\
v^{b}\left(M_{2}\right)-p_{2}^{b}-k(1-x)
\end{gathered}
$$

where $p_{1}^{b}$ and $p_{2}^{b}$ are the per transaction prices charged by issuing banks on platform 1 and by platform 2 respectively and $v^{b}(\cdot)$ is a positive (weakly) increasing function of the number of merchants affiliated to the same platform.

This functional form captures the idea that cardholders' benefits from holding a card are increasing in the expected number of merchants that accept the card they own. A widespread card acceptance by sellers makes it easier for the buyer to find a merchant accepting the card and therefore to conclude a transaction, and this effect is captured by the additive term $v^{b}(\cdot)$. The presence of cross-markets effects at the buyers and sellers level is a well known feature of the credit card industry. ${ }^{9}$ The formal analysis of these effects requires one to make assumptions about the ability of banks and platforms to affect buyers and sellers expectations and then the derivation of a fulfilled expectations equilibrium. The algebraic complexity of the model is greatly simplified by assuming away such effects at the customer level without altering the basic economics of the system; for this reason the main analysis will be conducted assuming $v^{b}$ as independent of the number of merchants adopting each platform. In the last part of the paper we reintroduce cross-markets effects and show how the qualitative results remain largely unchanged.

The proportion of buyers who are willing to use platform 1 is given by the location of the consumer indifferent between joining one or the other platform, and it is given by:

$$
c_{1}=\frac{1}{2}+\frac{p_{2}^{b}-p_{1}^{b}}{2 k}
$$

Similarly, the proportion of buyers willing to use platform 2 is:

$$
c_{2}=\frac{1}{2}+\frac{p_{1}^{b}-p_{2}^{b}}{2 k}
$$

\footnotetext{
${ }^{9}$ Network externalities have a number of implications for the evolution and efficiency of payment networks, see Economides (1993).
} 


\subsection{Sellers' behavior}

We adopt a specification of sellers' benefit of affiliation to a certain platform similar to that used for buyers. As for buyers, also a merchant faces an uncertainty since she/he does not know in advance which card a customer wishing to buy is holding in his pocket; using the same arguments as before, we assume that the affiliation decision is made on a per-transaction basis.

The benefit of selling the good through platform 1 and platform 2 are given by:

$$
\begin{gathered}
v^{s}\left(C_{1}\right)-p_{1}^{s}-t x \\
v^{s}\left(C_{2}\right)-p_{2}^{s}-t(1-x)
\end{gathered}
$$

where $p_{i}^{s}$ is the merchant discount charged on platform $i$ and $C_{i}$ is the expected number of cardholders on the same platform. As for the buyers, for the moment, we assume away cross-markets effects (that we will reintroduce in the last part of the paper) and let $v^{s}$ be a positive constant.

The location of the merchant indifferent between platform 1 and 2 gives the proportion of merchants willing to join platform 1; the remaining part of the segment is the proportion of merchants willing to affiliate to platform 2 . Formally:

$$
\begin{aligned}
& m_{1}=\frac{1}{2}+\frac{p_{2}^{s}-p_{1}^{s}}{2 t} \\
& m_{2}=\frac{1}{2}+\frac{p_{1}^{s}-p_{2}^{s}}{2 t}
\end{aligned}
$$

The two parameters $t$ and $k$ reflect the degree of substitution between the two platforms on the acquirers' and issuers' side respectively. The lower their values the more intense the competition between platforms. Since we are interested in the effects of different degrees of competition on the two sides, we keep $t$ constant and equal to 1 and let $k$ to vary. The parameter $k$ can then be interpreted as a relative measure of the degree of substitution between platforms on the two sides of the market. This results in little loss of generality because it turns out that, in equilibrium, the effect of changes in the two parameters are symmetric.

\subsection{Trading patterns and platforms' profits}

Platform profits depend on the number of transactions. Each pair (buyer, seller) on the same platform corresponds to a potential transaction; therefore, the number of total transactions on platform $i$ is a function the number of consumers adopting the card, $c_{i}$, and the number of merchants accepting it, $m_{i}, i=1,2$. Let us define $g_{i}\left(c_{i}, m_{i}\right)$ as the number of transactions on platform 
$i$; we first solve the model for the simplest possible scenario, that occurs when each consumer affiliated to platform $i$ makes one and only one transaction with each merchant accepting the same card; in this case, $g_{i}(\cdot)=c_{i} m_{i}$. In the economics of networks jargon, this scenario is defined as "balanced trading pattern"10.

Given the two expressions for platform 1 symmetric equilibrium prices, (2) and (3), profits for acquiring and issuing banks on platform 1 and profits for platform 2 are:

$$
\begin{aligned}
\pi_{1, A} & =(\sigma-1)\left(c_{A}+a\right) c_{1} m_{1} \\
\pi_{1, I} & =(\beta-1)\left(c_{I}-a\right) c_{1} m_{1} \\
\pi_{2} & =\left(p_{2}^{s}-c_{A}\right) c_{2} m_{2}+\left(p_{2}^{b}-c_{I}\right) c_{2} m_{2}
\end{aligned}
$$

where $c_{i}$ and $m_{i}, i=1,2$, are given in (6), (7) and (10), (11). Platform 1 total profits can be written as:

$$
\pi_{1}=H(a) c_{1}, m_{1}
$$

where

$$
H(a) \equiv(\sigma-\beta) a+(\beta-1) c_{I}+(\sigma-1) c_{A}
$$

is the per-transaction margin over total costs for platform 1. Clearly, if $\sigma=\beta$, i.e. same degree of intra-platform competition on both sides of the market, the per transaction margin is independent from the interchange fee while it increases (resp. decreases) with the interchange fee if $\sigma>\beta$ (resp. $<$ ). When competition among issuers is stronger $(\sigma>\beta)$, the per transaction margin is greater with a high interchange fee: setting a higher $a$ is a way to transfer funds from the more competitive side of the market to the less competitive (and more profitable) one ${ }^{11}$. The use the interchange fee to transfer funds across the two sides of the market is well known (see Baxter, 1983 and Wright, 2001); as it will become clear in the following section, it represents a crucial element also in our model.

\section{Equilibrium with balanced trading pattern, no externalities and constant markups}

We are now ready to solve the model and to study the characteristics of the optimal interchange fee. In this section we proceed in the simplest and more tractable case, namely when the trading pattern is balanced, there are no

\footnotetext{
${ }^{10}$ This is a standard assumption in the previous literature on credit cards; see, for example, Schmalensee (2002).

${ }^{11}$ The opposite applies when $\sigma<\beta$.
} 
externalities and platform 1 intra-network competition results in constant and exogenous price-cost markups.

In this very stylised framework, we are able to fully characterise the solution; in the last section of the paper we remove the above assumptions and we check the robustness of our results.

\subsection{The equilibrium for given interchange fee}

Platform 2 maximises profits taking $a, p_{1}^{b *}$ and $p_{1}^{s *}$ as given. From the usual first order conditions the optimal prices charged by platform 2 on the two sides, as a function of the interchange fee $a$, are:

$$
\begin{aligned}
p_{2}^{b}(a) & =\frac{2 k-1+(1-\sigma) c_{A}+(1+2 \beta) c_{I}-(\sigma+2 \beta) a}{3} \\
p_{2}^{s}(a) & =\frac{2-k+(1-\beta) c_{I}+(1+2 \sigma) c_{A}+(\beta+2 \sigma) a}{3}
\end{aligned}
$$

Using (2), (3), (16) and (17) we can derive the equilibrium total profits for the two platforms as a function of the interchange fee:

$$
\begin{gathered}
\pi_{1}(a)=\frac{(H(a)-5+k)(H(a)-5 k+1) H(a)}{36 k} \\
\pi_{2}(a)=\frac{(H(a)+k+1)^{3}}{108 k}
\end{gathered}
$$

Visual inspection of the second stage profit functions shows the following result:

Proposition 1. Suppose that platforms' competition is described by the above Hotelling model:

1. when intra-platform competition is symmetric $(\sigma=\beta)$, equilibrium platforms' profits are independent of the interchange fee;

2. platform 2 profits increase with the interchange fee if $\sigma>\beta$ and decrease otherwise.

Although the proof of the proposition above is straightforward, the economics behind it is not.

Consider an increase in the interchange fee; this produces the same qualitative effects on the prices charged by the two platforms, raising merchants' fees and lowering buyers' fees. This is obvious for platform 1 prices while for platform 2 it can be seen by taking the derivatives of expressions (16) and (17) with respect to $a: d p_{2}^{b}(a) / d a=-(2 \beta+\sigma) / 3$ and $d p_{2}^{s}(a) / d a=(\beta+2 \sigma) / 3$. 
The two derivatives have opposite sign and the absolute value of the second is larger than that of the first if $\sigma>\beta$.

The impact of an increase in the interchange fee on platform 2 profits' is therefore clear: when $\sigma>\beta$, a reduction of the price margin on the buyers' side is more than compensated by the price increase on the merchants' side and platform profits increase. For these same reasons, when $\beta>\sigma$, platform 2 profits are monotonically decreasing in the level of the interchange fee. When $\sigma=\beta$, the two effects cancel each other out; the net effect of a change in $a$ on profits is zero and this is true for both platforms.

This discussion shows how the setting of the interchange fee harms platform 2 , reducing its profits when certain conditions occur; in this respect, one of the main concerns of many regulatory authorities is that open systems, like Visa, may actually use the interchange fee to foreclose the market. The following corollary discusses this debated issue ${ }^{12}$.

Corollary 1. Provided that $a \in\left[-c_{A}, c_{I}\right]$, platform 1 cannot set the interchange fee so as to foreclose the market.

This result is interesting and suggests that the interchange fee cannot be used by platform 1 as an instrument to foreclose the market. Our message is therefore that market foreclosure should not be used as an argument for banning the interchange fee; we will proceed a bit further on these antitrust considerations in the next section, once derived the optimal interchange fee.

\subsection{The optimal interchange fee}

In the first stage platform 1, anticipating the second stage outcome, chooses the interchange fee to maximise total profits earned by banks participating to its network. As mentioned, we assume that side payments between issuing and acquiring banks are not allowed; this implies that the optimal interchange fee is constrained in the interval $\left[-c_{A}, c_{I}\right]$ to ensure non negative profits for member banks. Platform 1 maximisation problem is: ${ }^{13}$

$$
\begin{array}{cc}
\max _{a} & \pi_{1}(a) \\
\text { s.t. } & a \in\left[-c_{A}, c_{I}\right]
\end{array}
$$

\footnotetext{
${ }^{12}$ All proofs are in the Appendix.

${ }^{13}$ Note that although we adhere to the widespread definition of platform 1 as a "not-forprofit" entity, we recognise that this definition may be somehow misleading. Indeed platform 1 does not have its own profit to maximise; simply, it sets the interchange fee to maximise the sum of its members' profits.
} 
Let us define the following expressions:

$$
\begin{gathered}
a^{o p t}=\frac{1}{3} \frac{3(\beta-1) c_{I}+3(\sigma-1) c_{A}-4(k+1)+R}{\beta-\sigma} \\
G \equiv 1+\frac{4(k+1)-R}{3 c}
\end{gathered}
$$

and

$$
G^{\prime} \equiv 1+\frac{4(k+1)+2 R}{3 c}
$$

where

$$
R \equiv \sqrt{31-46 k+31 k^{2}}
$$

Proposition 2. In the Hotelling model of platform competition, the optimal interchange fee set by platform 1 is given by the following:

if $\sigma>\beta$

$$
a^{*}= \begin{cases}a^{o p t} & \text { if } \beta<G<\sigma<G^{\prime} \\ c_{I} & \text { otherwise }\end{cases}
$$

if $\beta>\sigma$

$$
a^{*}= \begin{cases}a^{o p t} & \text { if } \sigma<G<\beta<G^{\prime} \\ -c_{A} & \text { otherwise }\end{cases}
$$

The optimal interchange fee can assume both positive and negative values. Three variables crucially affect $a^{*}$ : the relative intensity of intra-platform competition on the two sides of the market captured by the sign of $(\sigma-\beta)$ and the relative intensity of inter-platform competition measured by $t$ and $k$. The next proposition states our main result concerning the role of the optimal interchange fee. Define the price level on each platform as the sum of buyers's fee and merchants' discount $P_{j}=p_{j}^{b}+p_{j}^{s}, j=1,2$ and the same-side platform price differential as $\Delta^{i}=p_{1}^{i}-p_{2}^{i}, i=b, s$.

Proposition 3. Let $\min \{\sigma, \beta\}<G<\max \{\sigma, \beta\}<G^{\prime}$. The optimal interchange fee sterilises the effects of different degrees of intra-platform competition on the equilibrium price levels, price differentials, total quantities and platforms profits.

This result is new. While previous papers have concentrated on the monopoly case or on competition between identical platforms, this Proposition shows that the optimal interchange fee makes platform 1 immune from the degree of competition between member banks on the issuing and acquiring side. Total profits for the platform will depend only on inter-platform competition, summarised by the parameter $k$ in the model. This result has interesting 
consequences; what really matters is competition between rival platforms, increasing competition within platforms is not associated with the usual effects on prices.

This also shows that non proprietary platforms have little incentive to impose entry barriers to new banks into the system since the effect of increased intra-platform competition is neutralised by the choice of the interchange fee. It should be noticed that the imposition of entry barriers by platforms is a concern of several regulatory authorities. Our main message is that, whereas for the issuing and acquiring banks the effect of increased intra-platform competition produces the obvious effect of decreasing the bank's individual profits, the total value of the platform, measured by the level of aggregate profits remains unchanged. Whether entry barriers are or are not lifted by open systems depends, therefore, on the governance mechanisms of this type of platform.

It is interesting to note that buyer's fees and merchants' discounts do depend on the conditions of market competition, both intra and inter-network; it is the total price level on each platform that is kept constant by means of the optimal interchange fee.

The competitive stance of platform 1 compared to platform 2 is not affected by its internal competition, as the constant price differentials $\Delta^{i}$ clearly demonstrate. Market shares on both sides of the market are also independent of the level of intra-platform competition. How the optimal interchange fee accomplishes this role is described in the next corollary.

Corollary 2. Let $\min \{\sigma, \beta\}<G<\max \{\sigma, \beta\}<G^{\prime}$. The optimal interchange fee $a^{*}$ exhibits the following properties:

1. If $\sigma=\beta$ then $a^{*}$ is undetermined;

2. $\operatorname{sign}\left(\frac{d a^{*}}{d \sigma}\right)=\operatorname{sign}\left(\frac{d a^{*}}{d \beta}\right)=\operatorname{sign}(\beta-\sigma)$;

3. If $k<1.43$ then $\operatorname{sign}\left(\frac{d a^{*}}{d k}\right)=\operatorname{sign}(\sigma-\beta)$; if $k>1.43$ the converse is true.

When $\sigma=\beta$, acquiring and issuing banks face the same degree of competition; the indeterminacy of the optimal interchange fee results, in our model, from the assumed symmetry of the intra-platform demand on the two sides of the market. Claim 2. is related to the effect of changes in the overall competition within platform 1 . The interchange fee is used by platform 1 as an instrument to balance prices on the two sides of the market. An increase in the overall degree of intra-platform competition (either $\sigma$ and/or $\beta$ decrease) is matched with a change in the interchange fee such that the price of the less competitive side is increased. On the contrary, platform 1 reacts to a reduction 
in the intra-platform degree of competition by lowering the price on the less competitive side. The effect on the price level $P_{1}$ is zero, but the two prices are pushed in opposite directions so as to keep them in balance. Summing up, the interchange fee is set to transfer funds to the less competitive (and more profitable) side of the market.

Claim 3. is related to the effect of inter-platform competition captured by the parameter $k$. The effect of changes in $k$ on the optimal interchange fee shows an intricate pattern. We identify a threshold level of $k$ such that below the threshold the sign of the derivative of $a^{*}$ with respect to $k$ is the same as the sign of $\sigma-\beta$; above the threshold the sign of the derivative is reversed. The basic intuition behind the result is the same as before: platform 1 uses $a$ in order to keep the two sides of the market balanced. To see this, consider the following scenario. Start from $k=t=1$ and assume that $\sigma>\beta$. This implies that inter-network competition has the same intensity on the two sides and that the acquirers' side is less (intra-network) competitive that the issuers' side; consequently acquirers earn higher margin than issuers, for a given interchange fee. If $k<t=1$, then both intra-platform and interplatform competition are stronger on the issuers' side. This depresses the price $p_{1}^{b}$; to balance the prices, following a reduction in $k$, platform 1 reduces $a^{*}$ thus increasing $p_{1}^{b}$ and lowering $p_{1}^{s}$. If $t=1<k<1.43$, inter-network competition is lower on the issuer side but the effect of $\sigma>\beta$ dominates so that a reduction in $k$ produces the same effect on $a^{*}$ as above. When $k>1.43$, inter-network competition is sufficiently weak to dominate the effect of stronger intra-platform competition on the issuers' side. In this range, a reduction in $k$ prompts an increase in $a^{*}$ so as to reduce $p_{1}^{b}$. Although in a different setting, this result is reminiscent of Guthrie and Wright (2003); these authors also show that network competition may lead to merchants being charged higher prices due to higher interchange fees. Summing up, this analysis shows how the interchange fee is used to keep balanced the prices on the two sides of the market, irrespective of the level of intra and inter-platform competition.

We conclude this discussion presenting the effects on platform 2 profits' of a ban on the setting of the interchange fee by the not-for-profit platform, a scenario that has been envisaged in the regulatory proposals of the Reserve Bank of Australia known as "balancing approach". Following Gans and King (2003), this regulatory approach involves a comparison of the costs of issuing and acquiring with the revenues obtained by each side of the credit card market. The basic idea is that the interchange fee can be used to offset any shortfall in revenue by either issuers or acquirers; since, in our model, both sides are financially viable, then there is no need to use the interchange fee to offset 
shortfalls and $a=0 .{ }^{14}$

Proposition 4. The impact of a ban on the setting of an interchange fee on platform 2 profits is ambiguous.

At the interior optimum,

$$
\pi_{2}\left(a=a^{o p t}\right)>\pi_{2}(a=0) \quad \text { if } \quad G>\frac{\beta c_{A}+\sigma c_{I}}{c_{A}+c_{I}}
$$

and

$$
\pi_{2}\left(a=a^{o p t}\right)<\pi_{2}(a=0) \quad \text { if } \quad G<\frac{\beta c_{A}+\sigma c_{I}}{c_{A}+c_{I}} .
$$

At the corner solutions,

$$
\pi_{2}\left(a=-c_{A}\right)>\pi_{2}(a=0) \Longleftrightarrow \beta>\sigma
$$

and

$$
\pi_{2}\left(a=c_{I}\right)>\pi_{2}(a=0) \Longleftrightarrow \sigma>\beta
$$

According to this result, regulations banning the setting of the interchange fee may produce perverse effects on the industry profits. Whether or not these will produce an increase in consumer surplus is a question for which our model is not well suited. The point we make is that such regulations may not be welcomed by all platforms.

\section{Verifying the robustness of the model}

So far, we have proceeded under the three simplifying assumptions of $i$ ) balanced trading pattern (i.e. each pair buyer/seller affiliated to the same platform corresponds to an actual transaction), $i i$ ) absence of cross-network effects and iii) constant and exogenous platform 1 price-cost markups. In this last section of the paper, we remove these assumptions in order to verify the robustness of the model. We start by considering a general unbalanced trading pattern.

\subsection{The model with unbalanced trading pattern}

The total amount of actual transactions on platform $i$, increases with the number of consumers and/or with the number of merchants affiliated to the same platform.

\footnotetext{
${ }^{14}$ For obvious reasons, a ban on the interchange fee is also strongly supported by the Australian Retailers Association; see ARA (2002). Note that if there is a shortfall in both sides of the market, the credit card association would not be financially viable.
} 
In the more general case, the trading pattern is unbalanced, namely a pair buyer/seller may or may not correspond to one transaction. Formally, the actual number of transactions taking place on platform $i, g_{i}\left(c_{i}, m_{i}\right)$, may be represented by any function of the number of platform $i$ 's affiliated consumers and merchants; clearly, $g_{i}(\cdot)$ is positively correlated with the number of consumers and merchants having adopted platform $i$ : $\partial g_{i} / \partial c_{i}>0$ and $\partial g_{i} / \partial m_{i}>0$.

A possible, and reasonably general, unbalanced trading rule may take the following form:

$$
g_{i}\left(c_{i}, m_{i}\right)=c_{i}^{\epsilon} m_{i}^{\eta} \quad \epsilon, \eta>0
$$

where $\epsilon$ and $\eta$ are positive constant; the more $\epsilon$ and $\eta$ differ from 1 the more unbalanced the trading pattern. In this case, it is possible to prove the following ${ }^{15}$ :

Corollary 3. Proposition 3 holds also for any unbalanced trading pattern of the form $g_{i}\left(c_{i}, m_{i}\right)=c_{i}^{\epsilon} m_{i}^{\eta}, \forall \epsilon, \eta>0$.

Formally, equilibrium profits, price levels and price differentials for this case are:

$$
\begin{gathered}
\pi_{1}=\frac{\left(\eta\left(k\left(2 \eta^{2}+1+5 \eta\right)+\eta+1\right)-A+8\right)\left(\eta\left(k\left(2 \eta^{2}+11+9 \eta\right)-\eta-5\right)+A-8\right)\left(\frac{A+8-\eta k\left(2 \eta^{2}+7 \eta+5\right)+\eta(3 \eta+11)}{4(2+\eta)^{2}}\right)^{\eta}}{8 k(2+\eta)^{3} \eta^{2}} \\
\pi_{2}=\frac{\left(\frac{2 \eta^{3} k+5 \eta k+5 \eta+\eta^{2}-A+7 \eta^{2} k+8}{4(2+\eta)^{2}}\right)^{\eta}\left(2 \eta^{3} k+5 \eta k+5 \eta+\eta^{2}-A+7 \eta^{2} k+8\right)^{2}}{8 k(2+\eta)^{4} \eta^{2}} \\
P_{2}=\frac{2(c+k) \eta^{3}+(7 k+2 c(3+\epsilon)+1) \eta^{2}+(5+4 c(\epsilon+1)+5 k) \eta-A+8}{2(\epsilon+1+\eta) \eta(2+\eta)} \\
P_{1}=\frac{2 \eta^{3} k+(2 c+5 k-1) \eta^{2}+(4 c+k+1) \eta-A+8}{2 \eta(2+\eta)} \\
\Delta^{b}=\frac{2 k(\epsilon-1) \eta^{3}+(5 k \epsilon-6 k+\epsilon) \eta^{2}+(5 \epsilon-4 k+k \epsilon) \eta-A \epsilon+8 \epsilon}{2(\epsilon+1+\eta) \eta(2+\eta)} \\
\Delta^{s}=\frac{2 \eta^{3} k+(7 k-1) \eta^{2}+(5 k-1-2 \epsilon) \eta+4-4 \epsilon-A}{2(\epsilon+1+\eta)(2+\eta)}
\end{gathered}
$$

where $A$ is given by

$\left(\eta\left(4 \eta^{4} k(\eta k+5 k-1)+\left(1-14 k+37 k^{2}\right) \eta^{3}+\left(2-24 k+38 k^{2}\right) \eta^{2}+\left(9-62 k+25 k^{2}\right) \eta+48-80 k\right)+64\right)^{\frac{1}{2}}$

From visual inspection, it is easy to check that also with unbalanced trading pattern, equilibrium platforms profits, price levels and price differentials are not affected by the degree of intra-platform competition, $\beta$ and $\sigma$. The immunisation role of the interchange fee perfectly applies also to this case.

\footnotetext{
${ }^{15}$ Clearly, $G$ and $G^{\prime}$ must be recomputed. The proof of this Corollary goes the same way as the proof of Proposition 3. For the sake of brevity we omit this proof but we make it available on request.
} 


\subsection{The model with network effects}

In this subsection we reintroduce cross-network effects at the individual level for buyers and sellers. The utility functions are those given in (4), (5) and (8), (9) and we assume a linear specification for the network effects: $v^{b}\left(M_{i}\right)=r M_{i}$ and $v^{s}\left(C_{i}\right)=v C_{i}$, with $i=1,2$, where the constant positive parameters $r$ and $v$ measure the strength of network effects.

The timing of the game remains unaltered. For each set of expectations, that we assume to be identical for all buyers and sellers, there is a corresponding equilibrium; the one we look at is derived imposing fulfilled expectations, where the expected size of each side of the market is equal to the actual one.

Buyers' and sellers' demand functions with network effects are:

$$
\begin{gathered}
c_{1}=\frac{1}{2}+\frac{p_{2}^{b}-p_{1}^{b}-v\left(M_{1}-M_{2}\right)}{2 k} \\
m_{1}=\frac{1}{2}+\frac{p_{2}^{s}-p_{1}^{s}-r\left(C_{1}-C_{2}\right)}{2 t} \\
c_{2}=1-c_{1} \quad m_{2}=1-m_{1}
\end{gathered}
$$

For the sake of simplicity we consider here the case of symmetric interplatform competition, $k=t=1$ only:

Corollary 4. Proposition 3 holds also with linear cross-network effects of the form $v^{b}\left(M_{i}\right)=r M_{i}$ and $v^{s}\left(C_{i}\right)=v C_{i}$, with $i=1,2$, and $v, r>0 .{ }^{16}$

The optimal interchange fee is then derived as above and is given by:

$$
a^{o p t}=\frac{(\sigma-1) c_{A}+(\beta-1) c_{I}}{\beta-\sigma}+\frac{12-3(t+v)}{(\beta-\sigma)(2(t+v)-9)}
$$

Clearly, for $v=0, r=0$, the above expression is equivalent to (20) with $k=1$. Proposition 3 holds, with the two conditions that ensure an interior solution appropriately modified ${ }^{17}$. As in the previous case, price levels, price differences and platform profits are independent of the degree of intra-platform competition. It can be shown that the equilibrium is characterised by the following:

$$
P_{1}=c+\frac{3(v+r)-12}{2(v+r)-9}, \quad P_{2}=c+\frac{2(v+r)-10}{2(v+r)-9}
$$

\footnotetext{
${ }^{16}$ We omit the formal proof of this Corollary. The proof runs along similar lines of those of previous sections. It is, however, available on request.

${ }^{17}$ In this case, $G=G^{\prime} \equiv 1+\frac{3(r+v)-12}{(2(r+v)-9) c}$.
} 


$$
\begin{aligned}
\Delta^{b}=\frac{v-1}{2(v+r)-9}, & \Delta^{s}=\frac{t-1}{2(v+r)-9} \\
\pi_{1}=3\left(\frac{v+r-4}{2(v+r)-9}\right)^{3}, & \pi_{2}=2\left(\frac{v+r-5}{2(v+r)-9}\right)^{3}
\end{aligned}
$$

Price levels, price differences and platform profits are instead affected by network effects. It actually turns out that network effects play a role similar to that of the inter-platform differentiation parameters $t$ and $k$ analysed in the previous sections. Intra-platform competition is not affected by the presence of network effects and, therefore, the immunisation result derived in Proposition 3 is still valid.

\subsection{The model with endogenous markups}

So far, we have proceeded under the assumption that on platform 1, intranetwork competition results in constant and exogenously given price-cost markups. While a constant margin is consistent with an iso-elastic demand function, in more general cases the price-cost margin also changes with the marginal cost. Since in our model, the marginal cost depends on the interchange fee which is endogenously determined, it is interesting to extend the model to the case of endogenous markups.

In a more general framework, when setting the interchange fee, platform 1 takes into account that the per transaction profitability of its member banks also changes. A reasonably general pricing rule to represent the relationship between price and marginal cost is to assume the following platform 1 equilibrium prices:

$$
\begin{gathered}
p_{1}^{s *}=\sigma c_{A}+\rho_{A} a \\
p_{1}^{b *}=\beta c_{I}-\rho_{I} a
\end{gathered}
$$

where $\rho_{i}>0$, with $i=I, A$, describes how much of the interchange fee is passed on to consumers and merchants by issuing and acquiring banks. Although formally $\rho_{i}$ may take any positive value, it is reasonable to assume $\rho_{i} \in[0,1]$ : when firm's marginal cost increases/decreases, usually the price charged to consumers increases/decreases less than proportionally.

Note that according to the above expressions, the price-cost markups now become:

$\frac{p_{1}^{s *}-\left(c_{A}+a\right)}{p_{1}^{s *}}=\frac{c_{A}(\sigma-1)-a\left(1-\rho_{A}\right)}{\sigma c_{A}+\rho_{A} a} \quad \frac{p_{1}^{b *}-\left(c_{I}-a\right)}{p_{1}^{b *}}=\frac{c_{I}(\beta-1)+a\left(1-\rho_{I}\right)}{\beta c_{I}-\rho_{I} a}$

which clearly do depend on $a$. 
When platform 1 equilibrium prices are described according to expressions (23) and (24), it is possible to prove the following ${ }^{18}$ :

Corollary 5. Proposition 3 holds also for platform 1 endogenous price-cost markups.

As for the general model, the interchange fee is used by platform 1 to balance the two sides of the market, and therefore it perfectly neutralises the impact of different degrees of cost pass-through $\rho_{I}$ and $\rho_{A}$ in the two sides of the market. Note that equilibrium platforms' profits, price levels and price differential are exactly the same as in section 3 .

Note that relaxing the assumption of exogenous markups may also be relevant in terms of platform 1 foreclosure strategy. When prices are given as in (2) and (3), the interchange fee is restricted to the interval $\left[-c_{A}, c_{I}\right]$ in order to guarantee non negative profits for member banks and Corollary 1 shows that when $a \in\left[-c_{A}, c_{I}\right]$ platform 1 cannot foreclose the market.

This constraint on the interchange fee rules out the possibility for equilibrium prices to be negative due to negative marginal costs. As suggested by Rochet and Tirole (2002): "the difference $\left(c_{I}-a\right)$ can be negative. A negative issuer marginal cost does not create the problem of unbounded consumption usually associated with negative marginal prices; for, even if the customer is offered cash-back bonuses or other inducements to use the card, the customer must still pay for the merchant's good-that is, he cannot use the card on a 'stand-alone basis'." 19

Although cash-back bonuses are never observed in the reality, it represents a situation that may occur at least theoretically: provided that the bonus is not greater then the price of the good, a negative price does not imply unbounded consumption and therefore it can be charged by the firms.

Formally, when prices are given as in expressions (23) and (24) and given that $0<\rho_{i}<1$, the interchange fee must belong to the following interval ${ }^{20}$ :

$$
a \in\left[\frac{\beta-1}{\rho_{I}-1} c_{I}, \frac{\sigma-1}{1-\rho_{A}} c_{A}\right]
$$

${ }^{18}$ The optimal interchange fee is now

$$
a^{o p t}=\frac{1}{3} \frac{3(\beta-1) c_{I}+3(\sigma-1) c_{A}-4(k+1)+R}{\rho_{I}-\rho_{A}} .
$$

Clearly, $G$ and $G^{\prime}$ must be recomputed. The proof of this Corollary goes the same way as the proof of Proposition 3. For the sake of brevity we omit this proof but we make it available on request.

${ }^{19}$ See Rochet and Tirole (2002), footnote 17. We thank Marius Schwart for having raised this point.

${ }^{20}$ The analysis also applies to the rather unrealistic case of $\rho_{i}>1$. 
In the Appendix, we prove that also in this case platform 1 cannot foreclose the market; that is, Corollary 1 applies also when platform 1 can set the interchange fee in a way such that its member banks are able to offer cashback bonuses.

\section{Conclusions}

Our aim was to shed new light on the determinants and the competitive role of the interchange fees set by not-for-profit associations facing competition by vertically integrated for-profit systems. Previous literature, surveyed in the introduction, has clarified the balancing role of the interchange fee in "getting both sides of the market on board". We show that the interchange fee plays the additional strategic role of making the competitive position of the not-for-profit platform, as opposed to the vertically integrated platform, independent from the conditions of intra-platform competition. When the interchange fee is set so as to maximise the sum of issuers' and acquirers' profits, the equilibrium values of platforms' profits, price levels and their market shares are independent of the competitive conditions within the not-for-profit platform and are affected by the strength of inter-platform competition.

Variations in the strength of competition, both inter and intra-platform, affect the level of the optimal interchange fee. An increase in the level of intraplatform competition, generating either from the issuers' or the acquirers' side, induces a change in the optimal interchange fee that increases the price of the less competitive side. This implies that if, for example, the acquirers' side is less competitive than the issuers' side, a further increase of competition on the issuing side will lead to an increase of the optimal interchange fee.

If inter-platform competition is not too asymmetric on the two sides, changes in its level produce the same effects on the optimal level of the interchange fee as those discussed above for intra-platform competition. Finally we show that a ban on the setting of the interchange fee by not-for-profit platform may harm its vertically integrated competitor.

The simple model we use does not lend itself to a rigorous welfare analysis; therefore we did not dwelled into the welfare properties of the equilibrium. This is a serious limitation of our model which we are trying to extend in order to accomodate this type of analysis. 


\section{References}

Armstrong, M. (2002). Competition in Two-Sided Markets. mimeo, University of Oxford.

Australian Retailers Association (2002). Reform of Credit Card Schemes in Australia - Response to the Reserve Bank of Australia Consultation Document. mimeo.

Baxter, W. F. (1983). Bank Interchange of Transactional Paper: Legal and Economic Perspectives. Journal of Law and Economics, 26:541-88.

Chang, H. H. and Evans, D. S. (2000). The Competitive Effects of the Collective Setting of Interchange Fees by Payment Card Systems. Antitrust Bulletin, Fall 2000:641-677.

Economides, N. S. (1993). Network Economics with Application to Finance. Financial Markets, Institutions $\&$ Instruments, 2:89-97.

European Commission (2002). Commission Exempts Multilateral Interchange Fees for Cross-Border Visa Card Payments. Press Release. DN: IP/02/1138. Brussels, July 2002.

Evans, S. and Schmalensee, R. (1999). Paying with Plastic. MIT Press, Cambridge MA.

Frankel, A. S. (1998). Monopoly and Competition in the Supply and the Exchange of Money. Antitrust Law Journal, 66:313-361.

Gans, J. and King, S. P. (2002). A Theoretical Analysis of Credit Card Regulation. mimeo, University of Melbourne.

Gans, J. and King, S. P. (2003). Approaches to Regulting Interchange Fees in Payment Systems. Review of Network Economics, 2:125-145.

Guthrie, G. and Julian Wright (2003). Competing Payment Schemes. University of Auckland, Working Paper n.245.

Parker, G. G. and Val Alstyne, M. W. (2000). Information Complements, Substitues, and Strategic Product Design. Working Paper n. 299, Tulane University.

Reserve Bank of Australia (2000). Debit and Credit Card Schemes in Australia: A Study of Interchange Fees and Access. mimeo, Camberra. 
Rochet, J. C. (2003). The Theory of Interchange Fees: A Synthesis of Recent Contributions. Review of Network Economics, 2:69-79.

Rochet, J. C. and Tirole, J. (2002). Cooperation among Competitors: the Economics of Payment Card Associations. RAND Journal of Economics, pages $1-22$.

Rochet, J. C. and Tirole, J. (2003). Platform Competition in Two-Sided Markets. Journal of the European Economic Association, forthcoming.

Schmalensee, R. (2002). Payment Systems and Interchange Fees. Journal of Industrial Economics, L:103-122.

Schwartz, M. and Vincent, D. R. (2001). Same Price, Cash or Card: Vertical Control by Payment Networks. Georgetown University, Working Paper 02-01.

VISA (2002). Response to the Reserve Bank of Australia's Consultation Document and Report of Professor Michael Katz. Prepared by: Network Economics Consulting Group.

Wright, J. Optimal Card Payment Systems. European Economic Review, forthcoming.

Wright, J. (2001). The Determinants of Optimal Interchange Fees in Payment Systems. University of Auckland, Department of Economics Working Paper 220 . 


\section{Appendix.}

Proof. of Corollary 1. Suppose that $\beta>\sigma$. In this case, platform 2 profits' decrease with $a$; for an interchange fee above a certain level, platform 2 makes negative profits (foreclosure). From (19) it is easy to see that $\pi_{2} \leq 0$ if

$$
a \geq \frac{k+1+(\beta-1) c_{I}+(\sigma-1) c_{A}}{\beta-\sigma}
$$

Clearly, this level of the interchange fee cannot be fixed by platform 1 since it is always grater than $c_{I}$. Similar arguments can be applied when $\sigma>\beta$; in this the level of the interchange fee which forecloses the market is always lower than $-c_{A}$ and cannot be chosen by platform 1 .

Proof. of Proposition 2. The solution to the unconstrained maximisation problem is given by $a^{o p t}$. The second order condition evaluated at $a=a^{\text {opt }}$ is:

$$
\left.\frac{d^{2} \pi_{1}}{d a^{2}}\right|_{a=a^{o p t}}=-\frac{(\beta-\sigma)^{2} R}{18 k}<0
$$

and it is clearly satisfied for all values of $k$. To complete the proof we need to verify $i$ ) under which conditions the constraints are satisfied and $i i$ ) the optimality conditions at the corners. Let us start with $i$ ) and assume that $\sigma>\beta$; we need to check when $a^{o p t}<c_{I}$ and $a^{o p t}>-c_{A}$. The first inequality holds for: $\sigma>G$, the second condition requires $\beta<G$. When one of the two is violated, the correspondent constraint binds. When $\beta>\sigma$ things are reversed. In order to check the optimality conditions at the corners, use (18) to compute platform 1 profits when $a=-c_{A}, a=c_{I}$ and $a=a^{o p t}$ :

$$
\begin{gathered}
\pi_{1}\left(-c_{A}\right)=(\beta-1) c \frac{[(\beta-1) c-5 k+1][(\beta-1) c-5+k]}{36 k}, \\
\pi_{1}\left(c_{I}\right)=(\sigma-1) c \frac{[(\sigma-1) c-5 k+1][(\sigma-1) c-5+k]}{36 k}, \\
\pi_{1}\left(a^{o p t}\right)=\frac{(R-4(k+1))(11 k-7+R)(7 k-11-R)}{972 k},
\end{gathered}
$$

Start from $\sigma>\beta$; it is easy to verify that in this case $\pi_{1}\left(c_{I}\right)>\pi_{1}\left(-c_{A}\right)$. Therefore we need to contrast $\pi_{1}\left(c_{I}\right)$ vs $\pi_{1}\left(a^{\text {opt }}\right)$; simple calculations show that for $\sigma>G^{\prime}$ profits of platform 1 are higher at the corner $\left(a=c_{I}\right)$ than when setting $a=a^{\text {opt }}$. Similar, but reversed, arguments apply when $\beta>\sigma$. 
Proof. of Proposition 3. The proof is very straightforward. Using (20) into the expressions for price levels $P_{j}$, gives the following:

$$
\begin{aligned}
& P_{1}=c+\frac{4(k+1)-R}{3} \\
& P_{2}=c+\frac{7(k+1)-R}{9}
\end{aligned}
$$

which show that the price levels are a constant margin above total costs. Equilibrium price differentials are:

$$
\begin{aligned}
\Delta^{b} & =\frac{7-2 k-R}{9} \\
\Delta^{s} & =\frac{7 k-2-R}{9}
\end{aligned}
$$

Finally equilibrium platform profits (18) and (19) become:

$$
\pi_{1}=\frac{(R-4(k+1))(11 k-7+R)(7 k-11-R)}{972 k}, \quad \pi_{2}=\frac{(7(k+1)-R)^{3}}{2916 k}
$$

As for quantities, the result easily follows from what we have already shown.

Proof. of Corollary 2. Claim 1. is clear from (20). To show claim 2. differentiate $a^{*}$ with respect to $\sigma$ and $\beta$ and get:

$$
\frac{d a^{*}}{d \sigma}=\frac{c_{I}-a^{*}}{\beta-\sigma}, \quad \frac{d a^{*}}{d \beta}=\frac{c_{A}+a^{*}}{\beta-\sigma} .
$$

It follows immediately that the numerator is positive in both cases so that the sign of the derivative is given by the sign of denominator.

Claim 3. is easily proved taking the derivative of $a^{*}$ with respect to $k$ :

$$
\frac{d a^{*}}{d k}=\frac{1}{3(\sigma-\beta)}\left[4+\frac{23-31 k}{R}\right]
$$

The term in square brackets is positive (negative) for $k<1.43(k>1.43)$; therefore the sign of the derivative is given by the sign of $(\sigma-\beta)$ if $k<1.43$ and by the opposite sign otherwise. 
Proof. of Proposition 4. From (19) and (20), $\pi_{2}\left(a=a^{o p t}\right)>\pi_{2}(a=0)$ if

$$
\frac{\left[k+1+(\beta-1) c_{I}+(\sigma-1) c_{A}\right]^{3}}{108 k}>\frac{[7(k+1)+R]^{3}}{2916 k}
$$

Getting rid of the power, dividing both parts by $3\left(c_{A}+c_{I}\right)$ and rearranging, this expression reduces to

$$
G>\frac{\sigma c_{A}+\beta c_{I}}{c_{A}+c_{I}}
$$

The right hand side of this inequality is a weighted average of $\sigma$ and $\beta$; therefore $\frac{\sigma c_{A}+\beta c_{I}}{c_{A}+c_{I}} \in[\min \{\sigma, \beta\}, \max \{\sigma, \beta\}]$. When $G>\frac{\sigma c_{A}+\beta c_{I}}{c_{A}+c_{I}}$, $\pi_{2}\left(a=a^{\text {opt }}\right)>\pi_{2}(a=0)$, when $G<\frac{\sigma c_{A}+\beta c_{I}}{c_{A}+c_{I}}$, then the reverse is true. The rest of the proof is straightforward; substituting for $a=-c_{A}$ and $a=c_{I}$ in the profit function (19) and comparing with the equilibrium profits for $a=a^{\text {opt }}$ yields the result.

Prof.: foreclosure with endogenous markups and $\rho_{A}, \rho_{I}<1 .{ }^{21}$ Let us define $a_{s x}=\frac{\beta-1}{\rho_{I}-1} c_{I}$ and $a_{d x}=\frac{\sigma-1}{1-\rho_{A}} c_{A}$. The model is defined for $a \in\left[a_{s x}, a_{d x}\right]$.

Platform 2 profits as a function of the interchange fee are:

$$
\pi_{2}(a)=\frac{\left((\beta-1) c_{I}+(\sigma-1) c_{A}+\left(\rho_{A}-\rho_{I}\right) a+k+1\right)^{3}}{108 k}
$$

Clearly, profits increase monotonically with $a$ if $\rho_{A}>\rho_{I}$ and decrease otherwise. Suppose $\rho_{A}>\rho_{I}$; in this case:

$$
\operatorname{sign}\left\{\frac{d \pi_{2}(a)}{d a}\right\}=\operatorname{sign}\left\{\left.\frac{d \pi_{2}(a)}{d a}\right|_{a=a_{s x}}\right\}
$$

where

$$
\left.\frac{d \pi_{2}(a)}{d a}\right|_{a=a_{s x}}=\frac{\left(1-\rho_{A}\right)(\beta-1) c_{I}+\left(1-\rho_{I}\right)(\sigma-1) c_{A}+\left(1-\rho_{I}\right)(k+1)}{108\left(1-\rho_{I}\right)^{3} k}>0
$$

Since $\pi_{2}(a)$ increases with $a$ then the above inequality shows that $\pi_{2}(a)$ is positive for any value of $a>a_{s x}$.

Similarly, suppose now that $\rho_{A}<\rho_{I}$; in this case:

$$
\operatorname{sign}\left\{\frac{d \pi_{2}(a)}{d a}\right\}=\operatorname{sign}\left\{\left.\frac{d \pi_{2}(a)}{d a}\right|_{a=a_{d x}}\right\}
$$

\footnotetext{
${ }^{21}$ Similar arguments apply when $\rho_{A}, \rho_{I}>1$.
} 
where

$$
\left.\frac{d \pi_{2}(a)}{d a}\right|_{a=a_{d x}}=\frac{\left(1-\rho_{A}\right)(\beta-1) c_{I}+\left(1-\rho_{I}\right)(\sigma-1) c_{A}+\left(1-\rho_{I}\right)(k+1)}{108\left(1-\rho_{A}\right)^{3} k}>0
$$

Since $\pi_{2}(a)$ decreases with $a$, then the above inequality shows that $\pi_{2}(a)$ are positive for any value of $a<a_{d x}$. This is sufficient to prove that $\pi_{2}(a)>0$, $\forall a \in\left[a_{s x}, a_{d x}\right]$. 